\title{
Effects of Mass Media Framing of Protest Movements: A Meta-Analysis and Systematic Review of Mass Media Studies
}

\author{
Geremew Chala Teresa ${ }^{1^{*}}$ \\ (D) 0000-0002-3424-6602 \\ ${ }^{1}$ Department of Afan Oromo, Literature and Communication, Haramaya University, ETHIOPIA \\ ${ }^{*}$ Corresponding author: geremew.chala@gmail.com
}

Citation: Teresa, G. C. (2022). Effects of Mass Media Framing of Protest Movements: A Meta-Analysis and Systematic Review of Mass Media Studies. Online Journal of Communication and Media Technologies, 12(2), e202208. https://doi.org/10.30935/ojcmt/11538

ARTICLE INFO

Received: 29 Aug 2021

Accepted: 22 Dec 2021

\section{ABSTRACT}

This study aimed to estimate an overall mean effect size of mass media framing of protest movements to provide an up-to-date overview of protest framing researches through a systematic review. Several scholars who have been engaged in framing researches were less consistent and lacked repeated stimuli in their findings, which inspired this study. This study used a rigorous systematic review to analyze protest movements of framing researches that addressed the effects of media framing of protest movements. Data were identified from two major databases and indexing services that produced 29 relevant studies included for analysis. The data were extracted with a structured format prepared in Microsoft Excel and copied to OpenMeta[analyst] software for analysis. Then, the pooled estimation of the outcomes was performed by the DerSimonian-Laird random-effects model at $95 \%$ confidence interval and produced an overall random weighted mean effect size of Pearson's product-moment correlation $(r)=0.352$.

Keywords: framing, mass media, meta-analysis, protests, systematic review

\section{INTRODUCTION}

The purpose of the present systematic review and meta-analysis is to report a combined result of various media framing of protest movements through empirical evidence. Although there are many studies on the effects of the protest paradigm that mainly emphasized framing as a theoretical justification, rare has been conducted on how news media reports protesters and social issues through empirical (Arpan et al., 2006). They often imagined protests and social issues as negative appraisals and emphasized that media framing of protest coverage often serves to delegitimize protesters and movements in the eyes of news consumers (Bennett \& Segerberg, 2015; Shoemaker, 1982). However, a peaceful protest that focuses on articulating issue positions is not likely to fit established news conventions for what makes a good news story. Thus, protest groups often find themselves in a double bind: be ignored by the media, or resort to drama and risk that these events might be used to delegitimize the group (Lee, 2018). In essence, the protest paradigm contributes to an escalation in tensions when activist groups feel that their voices are not being heard, leading conflicts away from healthy discourse toward more dysfunctional outcomes (McLeod, 2007).

In contemporary societies, mass media are tremendously important for social movements and protest groups (Hari, 2014; Mac Sheoin, 2013). Especially, the role of social media in mobilizing protest movement in our contemporary era have played significant roles (Goh \& Pang, 2016; Kaun, 2017; Lee, 2018). We suggest that social media can serve as a new venue of issues framing when societal conditions challenge the credibility and trustworthiness of established media and elite sources. When government authority and state media lose their credibility in the eyes of the citizens, social media can provide a new platform for issue framing (Surzhko-Harned \& Zahuranec, 2017). Protest groups often engage in activities that furnish the kind of drama that attracts considerable media attention which serves as a focal point for news coverage (Kilgo \& Harlow,

Copyright (c) 2022 by authors; licensee OJCMT. This article is an open access article distributed under the terms and conditions of the Creative Commons Attribution License (http://creativecommons.org/licenses/by/4.0/). 
2019; Leopold \& Bell, 2017; McLeod, 2007). Most, but not all, social movements and protest groups strive to get media attention and, if possible, positive media coverage, which in turn may be crucial to create favorable conditions for protesters (D'Angelo, 2017; Leopold \& Bell, 2017; Levin et al., 1998). Social movements and the actions they undertake are portrayed through mass media framing, whereby news is presented through identifiable lenses, which can shape public opinion (Boykoff, 2006). However, eventually, the mass media collectively serve as the arbiter of these framing contests by implementing and synthesizing their frames. By focusing more on the events organized by social movements and the characteristics of participants and less on the social issues that galvanized the contention and the context that informs it, the mass media depict protest activity in ways that can undercut the agenda of these movements (Boykoff, 2006).

As a result, media attention to protests tends to be negative, criticizing protesters as deviant and portraying them as ferocious (Leopold \& Bell, 2017; McLeod \& Hertog, 1999). The structural factors that shape news production make it difficult for protesters to control the nature of message framing (Boyle et al., 2012). Social movements must engage in 'framing contests' with political authorities if they hope to mobilize substantial protests (Brasted, 2005). Activists try to influence public perceptions in their framing of important issues in which solutions are workable, and why mobilization is worth the trouble (Cooper, 2002). Therefore, media attention is essential in helping a movement interconnect with the broad public to play a role that the media can play for social movements (Leopold \& Bell, 2017).

The scientific community has long acknowledged the importance of news framing of protests and social movements. Since the early 1960s and 1970s, many studies have been conducted, that analyzed how mass media present protest movements to various audiences. The number of these studies has risen to a point at which a systematic review and meta-analysis of research in the field is found paramount. As a result, this meta-analysis would be a ground contravention for scholars who wish to conduct a combination of research on the relationship between media framing of issues and protest movements. Through its coverage of events, the mass media, help construct meaning by framing patterns that may change well over time. However, social movement organizations must frequently take what they can get, and should exercise caution when the media is involved. Research suggests, for example, that how media frame issues affect audience views that can determine subsequent contributions and support from bystander publics, conscious constituents, and others (Baylor, 1996; Bennett \& Segerberg, 2015). In media organizations, journalists also play their role by choosing the storyline, and commentators develop arguments that support particular frames and affect the salience and intensity of issues (Cooper, 2002; Ketelaars, 2017). Various governments exert control of mass media mainly through negative news framing, which functions as a mechanism of social control to weaken the influence of social protests in public opinion (McLeod \& Hertog, 1992).

Existing literature on framing has demonstrated that framing effects are not universal, but produce inconsistent estimates of outcomes (Chong \& Druckman, 2007). I, therefore, believe that conducting a metaanalysis on mass media framing effects of protest movements can contribute to combining results of the inconsistent studies' outcomes in communication research. For example, although many framing researchers have been conducted on social mobilization, a few of them have tackled the effect of message consistency on the political consequences of protests (Wouters \& Walgrave, 2017).

This article provides a combination outcome of recent developments in the effects of mass media framing of protests. I contend that many trends in framing researches have neglected conducting systematic reviews and meta-analyses to report the consistencies and/or inconsistencies between media frames and broader issues of protests. This negligence is a product of conceptual problems in the definition of frames, the inattention to frame sponsorship, the failure to examine framing contests within broad political and social contexts of framing to a form of media effects. The early sociological framing studies like (Gitlin, 1980) advocated that framing processes require investigation within the context of the distribution of political and social power, which is suggested as a conflict frame. This tendency represents a considerable narrowing of the framing process by ignoring why some frames dominate news texts and why others do not (Carrage \& Roef, 2004).

Media framing of protests is crucial because of unavoidable volatile societal and political issues the public demand for media attention. Conducting a meta-analysis and systematic review of mass media framing effects of protests news is of conceptual value to our understanding of bias and distortions in information 
processing and persuasion is vital. Thus, citizens of the world have been providing several questions to the governments they belong to get attention for their issues via various means of communication and the media practitioners to create frames to organize and communicate the events they want to address (Leopold \& Bell, 2017; Watkins, 2001) need to be examined in a combined form of a meta-analysis.

In this meta-analysis, both effective and ineffective frames are determined equally effective because media framing of protests is often negatively or positively framed in general observation (Chong \& Druckman, 2007). This coincides with what Entman (1993) argued that the potential effects of frames are determined not only by what they include but also by what they exclude.

\section{Moderators of Framing Effects}

A sociological theorist, Erving Goffman, first introduced the concept of frame analysis to anticipate organizational and individual structures of experience they can have in their social lives (Goffman, 1974). Scholars such as Goffman (1974) and D'Angelo $(2002,2017)$ and other recent framing researchers pointed out that news frames are socially constructed through news media. However, framing effects are dependent on various factors that include media exposure, source characteristics, political attitudes, and passage of time (Buturoiu \& Corbu, 2015). According to D'Angelo (2002), the framing effect model has three sub-processes that indicate what frames affect various moderators

"ranged from official discourses of government figures, political candidates, and social movements, to audience frames that generate opinions of ordinary people in mundane conversations, to the prior knowledge underlying individuals' decision making and interpretations" (p. 880).

Entman (1993) argues that literature has witnessed that certain methodological and theoretical factors influence mass media framing effects. For example, Entman (1993) suggests that understanding audiences' autonomy, journalistic objectivity, textual and contextual messages of media and public opinion as some theoretical debates in the study of mass communication framing effects. On the other hand, Scheufele (2004) suggests that the theoretical and methodological critics of framing effects, such as the determination of experiment and field study after the presentation of stimuli do not lead to judgment. Moreover, the tendencies, frame elements, and media characteristics are other factors that need further investigation to what extent framing and evaluation of an issue interact.

This meta-analysis intends to examine other moderating variables that influence mass media framing of protest movements, which include the basis for samples, media type, general frame directions (positive/negative), and supports for status quo/protesters. According to Buturoiu and Corbu (2015), the influence of some moderation at the individual or contextual level can increase, decrease, or even congest framing effects. I hope these moderators could have a potential impact by assessing the magnitude of effect in media framing of protest movements via a systematic review and meta-analytic approach. The primary goal of this study is to combine a wide range of media framing effects of a protest movement in the broad field of political communication, whereas analyzing moderators that influence the effects of mass media framing of the protest movement is the second goal of this study.

\section{Research Questions}

To examine how the mass media framing of protests has evolved, this study uses a meta-analysis and systematic review approach to estimate the statistical average of existing empirical studies from 1990 to 2019 to get an updated estimate of the relationship between the media attention of protests and their framing effects. It will also examine what factors could potentially influence the magnitude of media framing protests and social movements. Therefore, the following research questions were proposed:

RQ 1: What is the overall effect sizes of mass media framing of protest movements in contemporary media studies?

RQ 2: To what extent is the effect of mass media framing of protest movements vary across different studies?

RQ 3: What moderating factors are interrelated with variability in effect sizes across mass media framing of protest studies? 


\section{METHODS}

\section{Literature Search}

The literature search focused on two major databases: 'Communication Source' and 'Sage Online Journals'. Although these two databases may not provide an exhaustive list of mass media framing of protest and social movement studies, they are the major databases that are mainly consulted in communication research. The literature search was restricted to peer-reviewed full-text English language academic journal articles published from January 1990 to December 2019 with the keywords "media framing of protests", "media coverage of protests", "media framing of collective action", "media framing of social movements", "media coverage of resistance", and "media framing of political mobilization". The search strategy resulted in the initial appearance of 3,335 articles from the databases. Other sources such as thesis, dissertations, conference papers, reports, and articles published in other languages were not included in the sample.

\section{Inclusion and Exclusion Criterion}

\section{Title and abstract stage}

At the title and abstract stage of the review, studies had to involve some form of media coverage of protest action, intervention, and comparison to be included. Finally, to meet the inclusion criteria at the title and abstract review stage, studies had to show a possible frame outcome that measured the aspect of media framing of protest-related effect. For any titles and/ or abstracts that did not contain enough information to determine effect sizes and if these criteria were met, the full text was roughly consulted to determine eligibility for inclusion. Based on these criteria, 3,232 studies were excluded from the initial search of 3,335 studies.

\section{Full-text stages}

As can be seen from the Preferred Reporting Items for Systematic Reviews and Meta-Analyses (PRISMA) diagram (Figure 1), the initial search generated 3,335 studies, of which 3,232 studies were excluded because of duplication, irrelevance, and unrelated research areas. The abstracts, hypotheses, and research designs, including the full-text level of the remaining 103 studies, were then reviewed and judged against the inclusion criteria at the full-text levels. 74 studies were finally excluded and the total number of identified studies that met the inclusion criteria at both titles/ abstract and full-text levels included in this meta-analysis was 29 . In general, studies should employ quantitative type research designs with the following study characteristics and statistical inquiries for this meta-analysis:

1. The study must focus on mass media framing of protests, social movements, and political communication and should gauge the effects of mass media framing of a social movement.

2. The study must include an empirical test of the media framing effect of the protest hypothesis and present a relationship between the media and protests within the circle of the framing effects.

3. The study must report sufficient and relevant information that enables the calculation of an index of effect sizes such as sample sizes, means, standard deviations, and other statistical correlations.

4. The study's effect size must be calculated using either Pearson's $r$ correlation statistics or their equivalent statistical transformation and conversion into the familiar metric of $r$.

For example, in this meta-analysis, studies that reported effect sizes in the form of Cohen's $d$ or standardized difference between means were converted into $r$ before calculating results under the metaanalytic model. Hence, this meta-analysis used Pearson correlation coefficient $r$ to measure the combined effect of mass media framing of protest movements using overall effect sizes, standard errors, at $95 \%$ confidence intervals $(\mathrm{Cl})$, measures of heterogeneity $(\mathrm{Q})$, or $\left(\mathrm{I}^{2}\right)$ statistics, and between-studies variance. Hunter and Schmidt (1990) recommend that the Pearson correlation coefficient $r$ is the most preferable measure of effect size in meta-analysis.

According to Rosenthal and DiMatteo (2001), Pearson's correlation coefficient $r$ has several advantages over Cohen's $d$. First, it represents the relationship between the independent variable and the dependent variable, but converting $r$ to the dichotomous $d$ loses information. Second, it allows for the analysis of trends across more than two groups, whereas $d$ is limited to two, and finally, $r$ is more simply interpreted in terms of 


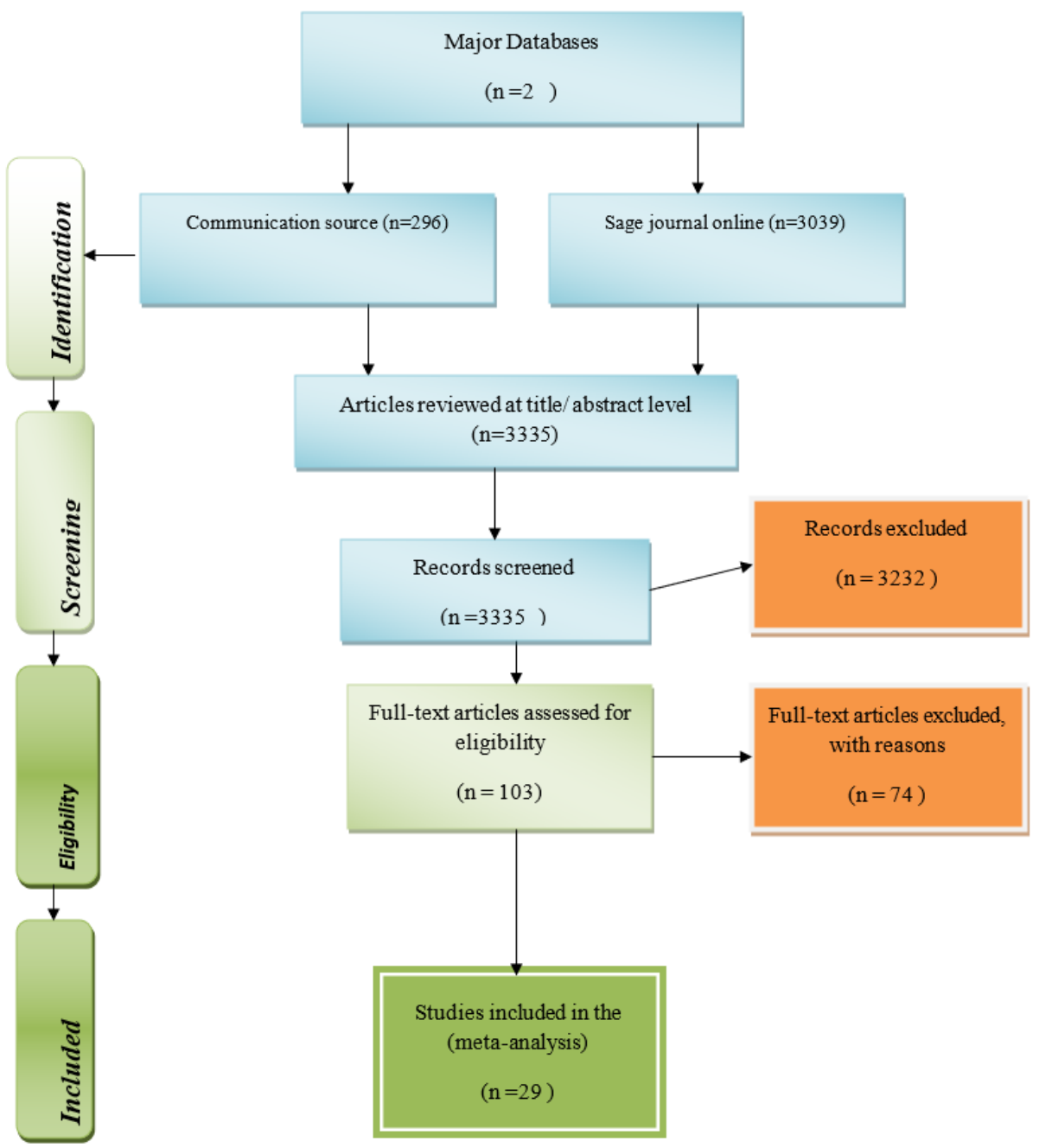

Figure 1. PRISMA flow diagram (adapted from Liberati et al. (2009))

practical importance than is $d$. Therefore, all effect size measures were converted into the Pearson productmoment correlation coefficient $r$.

\section{Data Extraction and Coding Procedure}

All the 29 studies that met the inclusion criteria were thoroughly reviewed and coded according to the coding book manual that was designed for guiding in conducting systematic review and meta-analysis was modified from the work of Luo et al. (2019). It contained the following categories: (a) Study name, (b) Year of publication, (c) Basis for $\mathrm{N}$ (sample) ( $0=$ human participant as a sample, $1=$ content category), (d) Study design (1=observational, $0=$ experimental), (e) Study sample size, and (f) Number of analysis. The coding manual also included moderators such as (a) media type (1=newspapers, $0=$ non-newspapers), (b) Frame direction ( $1=$ negative, $0=$ positive), and/or (c) Favoring group ( $1=$ =status quo, $0=$ protester/protests). Two coders were independently involved in the coding procedures of the studies using the coding manual mentioned above. The first coder was the author of this manuscript, and the other was a PhD candidate in Communication Science recruited by the author. The differences between the two coders were resolved through discussion until reaching $100 \%$ consensus for all coding elements.

\section{Statistical Analysis and Effect Size Calculation}

All the effect sizes for this analysis were reported in Pearson's product-moment correlation. The unit of analysis was each, which assumed one effect size per study however, in some studies, there was more than one effect size (see Table 1) that represents multiple groups (Luo et al., 2019). According to Borenstein et al. (2009), if different groups produced independent effect sizes in the same study, they must be treated as 
Table 1. Summary of basic characteristics of the studies included in the meta-analysis and systematic review

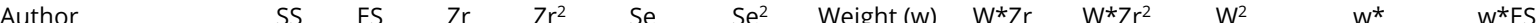

\begin{tabular}{|c|c|}
\hline 2006 & 234 \\
\hline
\end{tabular}

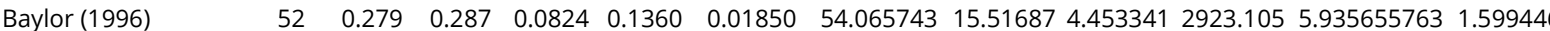

$\begin{array}{lllllllllllll}\text { Boykoff (2006) } & 358 & 0.282 & 0.290 & 0.0841 & 0.0510 & 0.00260 & 384.46751 & 111.4956 & 32.33372 & 147815.3 & 5.919760763 & 1.612162\end{array}$

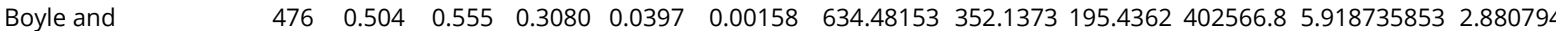

Schmierbach (2009)

Boyle et al. (2004)

Boyle et al. (2004)

Boyle et al. (2012)

Boyle et al. (2012)

Boyle et al. (2012)

Cooper (2002)

Cooper (2002)

Dardis (2006)

Detenber et al. (2007)

Fitzgerald (2016)

Gottlip (2015)

Harlow et al. (2017)

Kilgo and Harlow

$\begin{array}{lllllllllll}0.808 & 1.000 & 1.0000 & 0.1120 & 0.01254 & 79.719387 & 79.71939 & 79.71939 & 6355.181 & 5.929703763 & 4.627278\end{array}$

$\begin{array}{llllllllllll}280 & 0.232 & 0.236 & 0.0557 & 0.0583 & 0.00340 & 294.21369 & 69.43443 & 16.38653 & 86561.7 & 5.920558653 & 1.326503\end{array}$

$\begin{array}{llllllllllll}220 & 0.713 & 0.893 & 0.7974 & 0.0475 & 0.00226 & 443.21329 & 395.7895 & 353.44 & 196438 & 5.919416013 & 4.075894\end{array}$

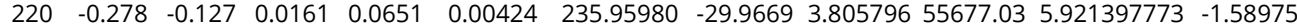

$\begin{array}{llllllllllll}220 & 0.473 & 0.514 & 0.2642 & 0.0597 & 0.00356 & 280.57652 & 144.2163 & 74.1272 & 78723.19 & 5.920723853 & 2.704543\end{array}$

$\begin{array}{llllllllllll}964 & -0.614 & -0.290 & 0.0841 & 0.0254 & 0.00065 & 1550.0031 & -449.501 & 130.3553 & 2402510 & 5.917804923 & -3.50897\end{array}$

$\begin{array}{llllllllllll}994 & -0.466 & -0.214 & 0.0458 & 0.0285 & 0.00081 & 1231.1480 & -263.466 & 56.38166 & 1515726 & 5.917972013 & -2.66324\end{array}$

$\begin{array}{llllllllllll}124 & 0.337 & 0.351 & 0.1232 & 0.085 & 0.007225 & 138.40830 & 48.58131 & 17.05204 & 19156.86 & 5.924384763 & 1.928149\end{array}$

$\begin{array}{llllllllllll}256 & 0.047 & 0.047 & 0.0022 & 0.0487 & 0.002372 & 421.64026 & 19.81709 & 0.931403 & 177780.5 & 5.919531453 & 0.268683\end{array}$

$\begin{array}{llllllllllll}611 & 0.042 & 0.042 & 0.0017 & 0.0405 & 0.00164 & 609.66316 & 25.60585 & 1.075446 & 371689.2 & 5.918800013 & 0.240069\end{array}$

$\begin{array}{llllllllllll}265 & 0.508 & 0.560 & 0.3136 & 0.053 & 0.002809 & 355.99857 & 199.3592 & 111.6412 & 126735 & 5.919968763 & 2.904284\end{array}$

$\begin{array}{lllllllllllll}553 & 0.312 & 0.323 & 0.1043 & 0.0405 & 0.00164 & 609.66316 & 196.9212 & 63.60555 & 371689.2 & 5.918800013 & 1.783369\end{array}$

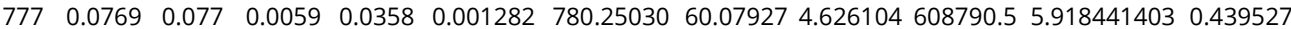

(2019)

McCluskey et al.

(2009)

McLeod and

Detenber (1999)

Oz (2016)

Oz (2016)

Shahin et al. (2016)

Smith et al. (2001)

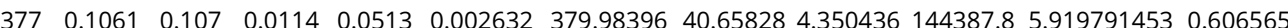

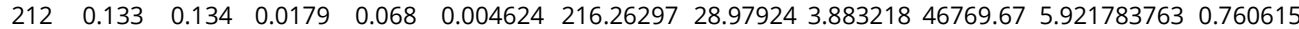

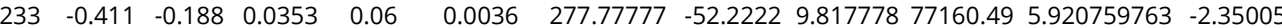

$\begin{array}{llllllllllll}533 & 0.3776 & 0.398 & 0.1584 & 0.0402 & 0.001616 & 618.79656 & 246.281 & 98.01985 & 382909.2 & 5.918775803 & 2.158325\end{array}$

$\begin{array}{llllllllllll}358 & 0.895 & 1.000 & 1.0000 & 0.0236 & 0.000557 & 1795.4610 & 1795.461 & 1795.461 & 3223680 & 5.917716723 & 5.114784\end{array}$

$\begin{array}{llllllllllll}635 & 0.499 & 0.550 & 0.3025 & 0.0344 & 0.001183 & 845.05137 & 464.7783 & 255.628 & 714111.8 & 5.918343123 & 2.852019\end{array}$

$\begin{array}{lllllllllllll}635 & 0.288 & 0.296 & 0.0876 & 0.0381 & 0.001452 & 688.89026 & 203.9115 & 60.35781 & 474569.8 & 5.918611373 & 1.646132\end{array}$

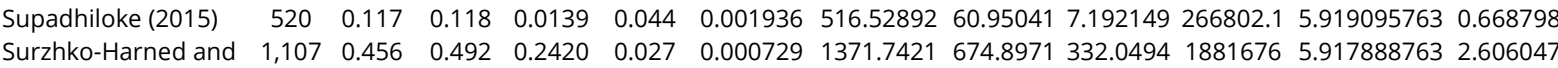
Zahuranec (2017)

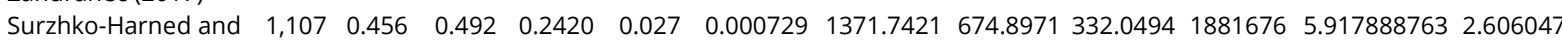
Zahuranec (2017)

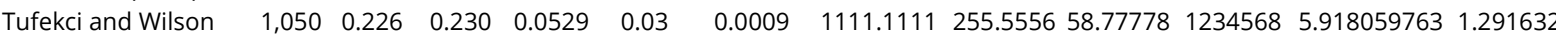

(2012)

Veneti et al. (2016)

Weaver and Scacco

(2013)

Weaver and Scacco $\quad 200 \quad-0.059 \quad-0.029 \quad 0.0008 \quad 0.071 \quad 0.005041 \quad 198.37333 \quad-5.75283 \quad 0.166832 \quad 39351.98 \quad 5.922200763 \quad-0.33744$ (2013)

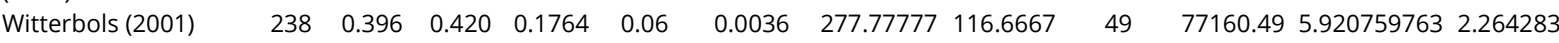

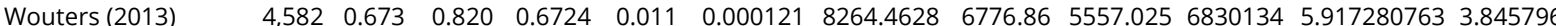

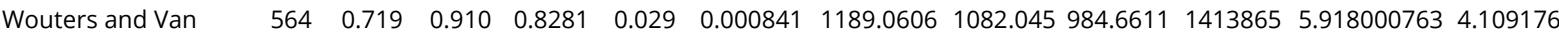
Camp (2017)

Woutersa and

Walgrave (2017)

Xu (2013)

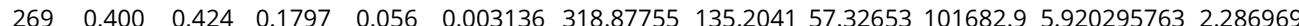

Young (2013)

Sum

$\begin{array}{llllllllllll}132 & 0.820 & 1.000 & 1.0000 & 0.05 & 0.0025 & 400.00000 & 400.0000 & 400.000 & 160000 & 5.919659763 & 4.687764\end{array}$

$\begin{array}{lllllllllllll}103 & 0.541 & 0.610 & 0.3721 & 0.084 & 0.007056 & 141.72335 & 86.45125 & 52.73526 & 20085.51 & 5.924215763 & 3.095246\end{array}$

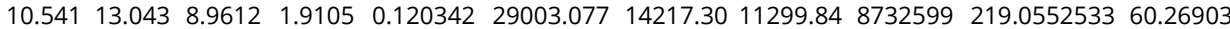

All effect sizes were presented in Pearson's correlation $r$. Conversions were made if studies did not report in $r$ from other reporting measures of effects. The original data were the basis for all the calculations computed. The values displayed in the table headings, ES=Effect Size, Zr=Fisher's transformation of the correlation, Se=standard error, ES=Effect Size, W=weight, wi*=random-effects weights, SS=sample size

separate studies because independent effect sizes contributed independent information to the grand mean effect size. If the groups did not possess independent variables, the overall correlation was computed and used, and if the subgroups had different sample sizes, a weighted average was used for possible computation (Luo et al., 2019). All effect sizes were calculated and converted into $r$ using either of the following formulae:

$$
r=\frac{d}{\sqrt{d^{2+4}}}
$$

Computing $r$ from an independent t-test,

$$
\begin{aligned}
& r=\frac{\sqrt{t^{2}}}{t^{2+d f}} \\
& r=\sqrt{\frac{x_{(1)}^{2}}{N}}
\end{aligned}
$$




$$
\begin{gathered}
r=\sqrt{\frac{F(1, d f)}{F(1, d f)+d f}} \\
r=\frac{Z}{\sqrt{N}}
\end{gathered}
$$

Online calculators from the information given in the original studies have also been implemented for some studies (https://www.psychometrica.de/effect_size.html, https://campbellcollaboration.org/escalc/html/ EffectSizeCalculator-SMD-main.php). When all data were not available to the computer, conversion formulas were utilized, following prior recommendations (Lipsey \& Wilson, 2001).

The weight in all analyses is defined as the inverse of the variance or $w=1 / S E^{2}$, where the variance, $S E^{2}$, is strongly related to sample size (Card, 2012):

$$
Q=\sum\left(w_{i} E S_{i}^{2}\right)-\frac{\left(\sum w_{i} E S_{i}\right) 2}{\sum w_{i}}
$$

To calculate the weighted mean effect size, I used the following formula, which was proposed by Card (2012, p. 239):

$$
\overline{Z r}=\frac{\sum w i * Z r}{\sum w i *}
$$

The standard error of the mean effect size, $z$ test, and the lower and upper bounds of the 0.95 confidence intervals was then calculated using:

$$
\begin{aligned}
S E_{\overline{Z r}} & =\sqrt{\frac{1}{\sum w *_{i}}} \\
Z & =\frac{\overline{Z r}}{E S_{\overline{Z r}}}
\end{aligned}
$$

where $E S$ is the mean effect size across studies and $E S_{\overline{Z r}}$ is the standard error of the mean effect size.

$$
I^{2}=\left(\frac{Q-d f}{Q}\right) \times 100 \%
$$

A random-effects model meta-analysis, which was proposed by Hedges and Vevea (1998), was conducted to respond to the research questions of this meta-analysis. "Meta-analysis serves two important functions by making it possible to (a) compute a weighted mean effect size from a sample of cases, and (b) test moderating variables that may explain inconsistent findings in a body of research" (Banas \& Rains, 2011, p. 277-278). According to Anker et al. (2010), a random model is applied for a between-studies variance in computing the overall weighted mean effect size and the $95 \%$ confidence interval. Hence, I preferred the random-effects model for this meta-analysis, because the random-effects model helps to make more conclusions that are generalizable, and the presence of studies that are outliers in terms of either their effect sizes or their standard errors is better managed in random than fixed-effects models (Card, 2012).

\section{RESULTS}

A total of 29 studies involving 37 cases of a systematic review of media framing and protest movements outcomes emerged from published studies between January 1990 to December 2019 for inclusion in the review. The 29 studies with 37 different cases were systematically analyzed. Finally, the effect sizes of the cases $(k=37)$ were calculated using Pearson product-moment correlation coefficients $r$, and their equivalent metric transformations were made.

\section{Study Characteristics}

As depicted in Table 1, 29 studies with 37 study events were included in the systematic review and metaanalysis. An average of 416 individuals $(k=6)$ from the survey participants and 576 textual analyses $(k=31)$ from the content-based analysis were included in the meta-analysis sample. The sampled population characteristics included from survey participants ranged from 212 to 1,050, while the sampled population characteristics from news articles and textual analysis ranged from 52 to 4,582. The types of media included in this meta-analysis were newspapers $(k=18)$, televisions $(k=8)$, social media $(k=4)$ and mixed $(k=7)$. Regarding 
Table 2. Subgroup analysis based on the sample category of the studies

\begin{tabular}{lccccc}
\hline Basis for sample & $\begin{array}{c}\text { Number of the } \\
\text { studies }\end{array}$ & $\%$ & $\begin{array}{c}\text { Effect size estimates } \\
(95 \% \mathrm{Cl})\end{array}$ & $\begin{array}{c}\text { Heterogeneity } \\
\left(\mathrm{I}^{2}\right)\end{array}$ & $\mathrm{p}$-value \\
\hline Content-based categories & 31 & 83.78 & $0.363(0.212,0.513)$ & $99.27 \%$ & $\mathrm{p}<0.001$ \\
Survey-based categories & 6 & 16.22 & $0.2 .99(0.142,0.457)$ & $94.27 \%$ & $\mathrm{p}<0.001$ \\
Overall & 37 & 100 & $0.352(0.220,0.484)$ & $99.17 \%$ & $\mathrm{p}<0.001$ \\
\hline
\end{tabular}

frame direction, $(k=26)$ negative for protesters, i.e., framed in favor of status quo and $(k=11)$ framed in a positive direction for protests/protesters. The effects of mass media framing of protests ranged from $r=-0.614$ to 0.895 .

Overall, the weighted grand mean effect size correlation was $0.352(95 \%$ confidence interval $(\mathrm{Cl})=[0.220$, $0.484, p<0.001])$. The weighted mean value of the effect size was significantly smaller with $Z=77.19 d f=36$, $p<0.001$. This value indicates that mass media framing of the protest movement is nearly at a medium level based on Cohen's (1992) magnitude estimation of effect size. Using a random-effects model of heterogeneity analysis revealed that, there was a large degree of heterogeneity at $\left(I^{2}=99.17 \%, p<0.001\right)$ across the studies. This overall grand mean correlation of effect size was significantly heterogeneous with $\operatorname{tau}^{2}=0.165, Q=4330.52$, $d f=36, \mathrm{p}<.001$. The significant result of the $\mathrm{Q}$ statistic shows that there is high variability across the included studies (Lipsey \& Wilson, 2001). The larger $\mathrm{I}^{2}$ index static shows that there is speculation about the reasons for the variance and the possibilities to apply different techniques of moderator analysis (Borenstein et al., 2009). The above heterogeneity index of the overall mean effect size of mass media framing of protest movement can be estimated as considerable heterogeneity based on the heterogeneity index speculations (Higgins \& Green, 2008). This study assumed the random-effects model because it is assumed that "the true effect size varies from study to study, and the summary effect is our estimate of the mean of the distribution of effect sizes" (Borenstein et al., 2009, p. 6). Figure 2 illustrates that the pooled estimates the overall mean effect size in the present meta-analytic review.

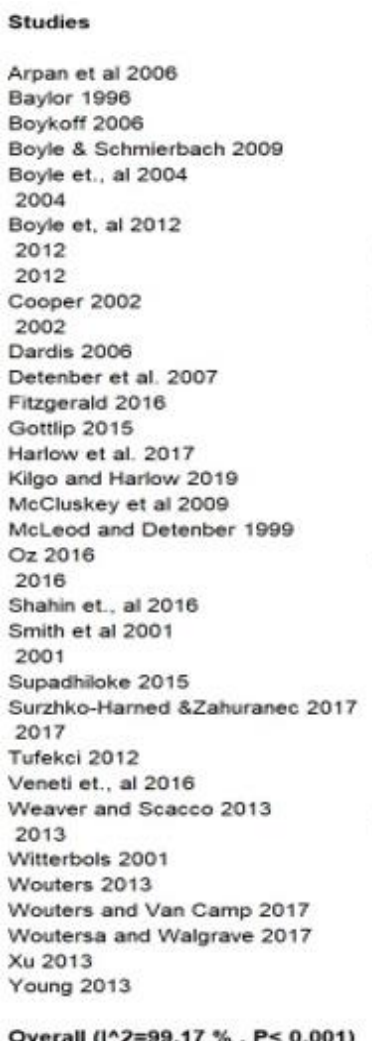

\begin{tabular}{|c|c|c|}
\hline \multicolumn{2}{|c|}{ Estimato $\langle 95 \%$} & \multirow{2}{*}{$\begin{array}{l}\text { C.I.) } \\
0.520)\end{array}$} \\
\hline 0.400 & 80 , & \\
\hline 287 & 10.020 . & $0.554)$ \\
\hline .290 & 80.190 , & $0.390)$ \\
\hline 0.555 & 80.477 , & $0.633)$ \\
\hline 1.000 & 10.780 & $1.220)$ \\
\hline 0.236 & 80.122 , & $0.350)$ \\
\hline 0.893 & 10.800 & $0.986)$ \\
\hline 0.127 & s-0.255, & $0.001)$ \\
\hline 0.514 & 10.397 , & $0.631)$ \\
\hline-0.290 & $1-0.340$ & $-0.240)$ \\
\hline 0.214 & $1-0.270$ & $-0.158)$ \\
\hline 0.351 & 10.184 , & $0.518)$ \\
\hline 0.047 & $\{-0.048$, & $0.142)$ \\
\hline 0.042 & $1-0.037$, & $0.121)$ \\
\hline 0.560 & 10.456 & $0.664)$ \\
\hline 0.323 & 10.244 , & $0.402)$ \\
\hline 0.077 & 10.007 , & $0.147)$ \\
\hline 0.107 & 10.006 & $0.208)$ \\
\hline 0.134 & 10.001 , & 0.2677 \\
\hline-0.188 & $1-0.306$ & $-0.070)$ \\
\hline 0.398 & 10.319 , & 0.4777 \\
\hline 1.000 & 10.954 , & $1.046)$ \\
\hline 0.550 & $(0.483$, & $0.617)$ \\
\hline 0.296 & 10.221 & $0.371)$ \\
\hline 0.118 & 10.032 , & $0.204)$ \\
\hline 0.492 & 10.439 , & 0.545 \\
\hline 0.492 & 10.439 , & $0.545)$ \\
\hline 0.230 & 10.171 & $0.289)$ \\
\hline 0.343 & 10.250 & $0.436)$ \\
\hline 0.028 & $\{-0.167$, & 0.1111 \\
\hline 0.029 & $1-0.168$ & $0.110)$ \\
\hline 0.420 & 10.302 . & $0.538)$ \\
\hline 0.820 & 80.798 , & $0.842)$ \\
\hline 0.910 & 10.853 & $0.967)$ \\
\hline 0.424 & 10.314 , & $0.534)$ \\
\hline 1.000 & 10.902 , & $1.098)$ \\
\hline 0.610 & 10.445 , & $0.775)$ \\
\hline & 0.220 , & s. \\
\hline
\end{tabular}

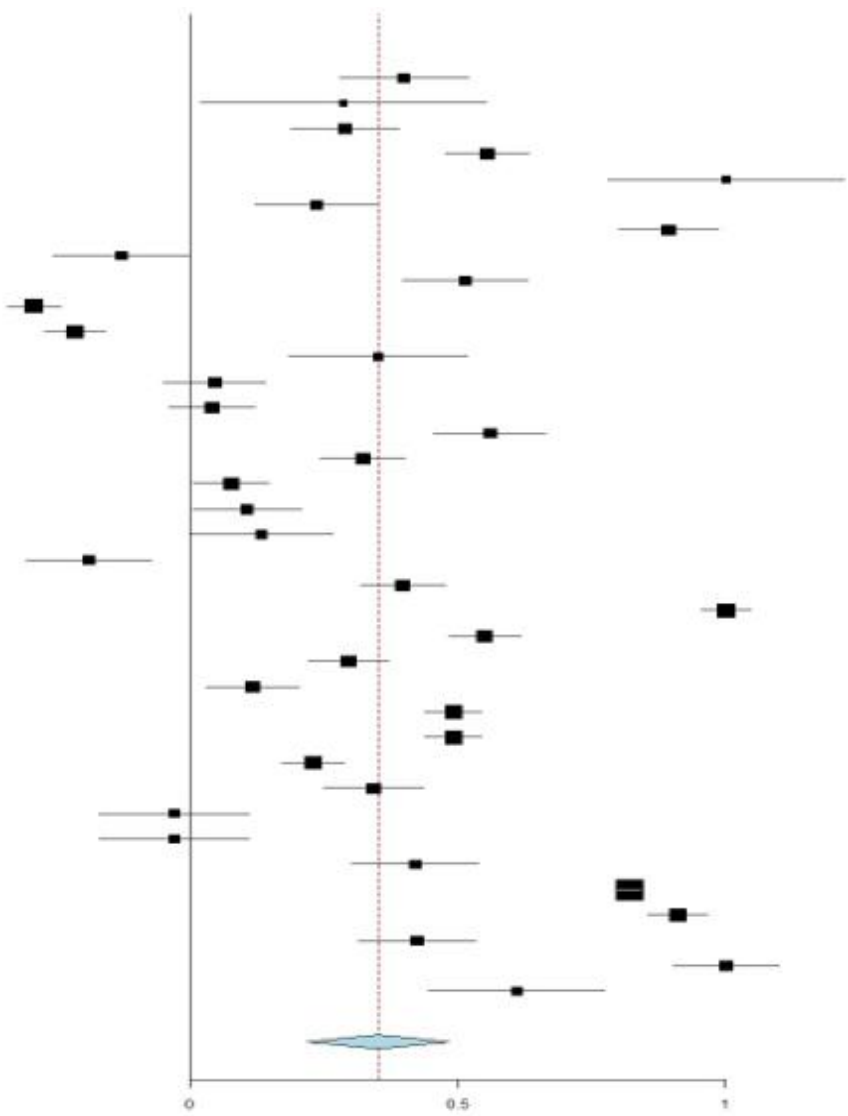

Figure 2. Forest plot illustrating the overall effect size of 29 studies reporting mass media framing of a protest movement 
To estimate the population variability of all the studies, I partition the observed heterogeneity into the expectable sampling fluctuations and which represent true deviations in population effect sizes. Since it is impossible to know whether the extent of a particular study's deviation is due to sampling error or distribution of population effect sizes, I decided to make both the estimation of magnitude. The population variability in effect sizes $\left(\tau^{2}\right)$ was computed using the following equation:

$$
\tau^{2}=\frac{Q-(k-1)}{\sum w_{i}-\frac{\sum w_{i}^{2}}{\sum w_{i}}}
$$

Based on the above formula proposed by Card (2012, p. 236), I computed the estimated population variability in the effect sizes of the present meta-analytic review, which accounted for 0.169 . This estimated population variability is almost similar to the output of the OpenMeta[analyst] software I ran for the same purpose i.e. 0.165. It was found important to first compute the estimates of population variability (tau square $/ \tau^{2}$ ) before computing the new random-effects weights for each study in the meta-analysis because random-effects weights are more logical to the normal weighted effect sizes to give precise effects (Card, 2012). Therefore, the random-effects weights for this meta-analysis were computed using the formula, $w *=$ $1 / \tau^{2}+S E_{i}^{2}$. Hence, the random-effects weights for all the studies included in this meta-analysis are shown in Table 1, second column from the right side.

Therefore, the significant result of $\mathrm{I}^{2}$ necessitated the analysis of moderators that affect the increase or decrease in the effects of mass media framing of protest movements. Based on the data produced and extracted from the original studies, the following sub-groups of moderators has been analyzed using the OpenMeta[analyst] software. These were the basis for analysis (survey/content), type of media (newspaper/TV/social media or mixed), and status quo support/protests/protesters support.

All these moderators played significant roles in the observed heterogeneity across the study. As depicted in Table 2, the weighted mean effect size of the content-based studies was $0.363(95 \% \mathrm{Cl}: 0.212,0.513)$, while the weighted mean effect size of the human participant survey-based studies was 0.299 ( $95 \%$ Cl: $0.142,0.457$ ). The OpenMeta[analyst] software produced the highest heterogeneity measures for both of the variables with $\left(I^{2}=99.27 \%, p<0.001\right)$, and $\left(I^{2}=94.27 \%, p<0.001\right.$ for the content-based category and survey based-category, respectively.

The outcome of this meta-analysis showed that, there is a relatively bigger effect size in the content category studies that account to be a mean effect size of $r=0.363$ than the survey category with a mean effect size of $r=0.299$. This result confirms that studies such as McCombs and Shaw (1972), Wanta and Wu's (1992), and Luo et al. (2019) found out that communication studies using content categories from text analysis produce bigger effect sizes than communication studies using survey categories. The reason for these premises was that, studies that used content categories analyzed the data at the aggregated level, while the studies that used survey categories analyzed the data at the individual level (Luo et al., 2019; McCombs \& Shaw, 1972).

Scholars believe that it is important to disentangle the method variables from substantive variables in the meta-analysis (Cooper et al., 2019). According to Lipsey (2003), variation in study effect sizes is the issue related to methodological differences among the studies. However, the decision of effect size with type of subjects, or categories of sub-groups substantive variables often considered as theoretical or practical importance (Cooper et al., 2019). Thus, the present meta-analysis was conducted mainly based on a systematic analysis of the relationships between study descriptors and effect sizes initially coded from primary studies. The confound relationship of media framing of protests movement and its effects are somewhat ambiguous. This is because one of the limitations of substantive moderator variables in observational studies is their effect sizes related to each other in which it is ambiguous to know or measure the influential variables (Cooper et al., 2019).

In addition to computing the effects of the overall studies, I have conducted a subgroup analysis based on the media type, effect direction, and supporting groups (status quo/protesters). The effect of studies involving mixed media type on protest movement was relatively the highest effects observed from media type moderators, and the effect television media type was the lowest effect size measures. For each subgroup analysis, I ran OpenMeta[analyst] and then, summarized its outcome into different tables for simplification. 
Table 3. Subgroup analysis based on the media type of the studies

\begin{tabular}{lccccc}
\hline The media type of studies & $\begin{array}{c}\text { Number of the } \\
\text { studies }\end{array}$ & $\%$ & $\begin{array}{c}\text { Effect size estimates } \\
(95 \% \mathrm{Cl})\end{array}$ & $\begin{array}{c}\text { Heterogeneity } \\
\left(\mathrm{I}^{2}\right)\end{array}$ & $\mathrm{p}$-value \\
\hline Newspapers & 18 & 47.37 & $0.348(0.116,0.581)$ & $99.27 \%$ & $\mathrm{p}<0.001$ \\
Television & 8 & 21.05 & $0.283(-0.045,0.612)$ & $98.85 \%$ & $\mathrm{p}<0.001$ \\
Social media & 4 & 13.16 & $0.385(0.253,0.517)$ & $94.91 \%$ & $\mathrm{p}<0.001$ \\
Mixed & 7 & 18.42 & $0.423(0.192,0.654)$ & $98.37 \%$ & $\mathrm{p}<0.001$ \\
Overall & 37 & 100 & $0.352(0.220,0.484)$ & $99.17 \%$ & $\mathrm{p}<0.001$ \\
\hline
\end{tabular}

Therefore, as depicted in Table 3, the sub-group analysis based on the type of media included in the metaanalysis and systematic review revealed that there is relatively the highest pooled estimate in mixed media studies, $0.423(95 \% \mathrm{Cl}: 0.192,0.654)$ with a degree of heterogeneity of $\mathrm{I}^{2}=98.37 \%$ at a $p$-value of $<0.001$. This was followed by the social media studies type with an effect size magnitude of 0.385 ( $95 \% \mathrm{Cl}: 0.253,0.517)$ and a degree of heterogeneity of $\mathrm{I}^{2}=94.91 \%$ at $\mathrm{p}<0.001$. The newspapers' media studies type accounted for an effect size of $0.348(95 \% \mathrm{Cl}: 0.166,0.581)$ with the degree of heterogeneity of $\mathrm{I}^{2}=99.27 \%$ at $\mathrm{p}<0.001$ significance level. Nearly $0.283(95 \% \mathrm{Cl}-0.045,0.612)$ was reported in TV news with a degree of heterogeneity $\mathrm{I}^{2}=98.85 \%$ at $p<0.001$. The effect sizes for all media types were significant at $(p<0.001)$. However, the analysis shows that studies involving mixed media and social media types of framing of protest movements generate significantly more effects than newspaper and TV study types. From Table 3, we can understand that studies involving more than one media type or a mixture of more than one media type revealed the strongest estimates of the effects of mass media framing effects and was followed by social media type and studies involving television media type revealed the least estimate effect size.

All the degrees of heterogeneity were in $I^{2}$ static. However, a check made shows that degrees of heterogeneity in $1^{2}$ were almost the same in $\mathrm{Q}$ static. The larger the effects of mass media on the protest movement observed in the social media in this study confirms that the stronger the repetitive news framing produced because of better information accessibilities (Buturoiu \& Corbu, 2015). Social media sites are the most accessible and popular media type that can affect the participation of citizens in civic and political communication (Boulianne, 2015), which can lead to significant media effects of the protest movement (Lee, 2018). However, the regulatory systems, which are not relatively as free as social media did not allow other media, types such as TV and newspapers.

As can be seen from Table 4, the effects of mass media framing of protest movements based on either status quo or protest/protester support subgroup analysis indicated that status quo support overweighed protest/protesters with a pooled effect size estimates $r=0.362$. As can be seen from Table 4, the overall effect size of the status quo supports media framing effects of the protest movement was 0.362 (95\% Cl: 0.181, $0.543 ; \quad p<0.001)$ with a $99.35 \%$ degree of heterogeneity $\left(I^{2}\right.$ static). However, the effect size of protester/protesters was 0.329 (95\% Cl: $0.205,0.454 ; \mathrm{p}<0.001)$ with a $96.56 \%$ degree of heterogeneity measure in $1^{2}$ static. This result confirms that mass media are generally less critical of groups in power but support the status quo and marginalize the opposing groups (Mac Sheoin, 2013; McLeod \& Detenber, 1999). This can be illustrated by Kahneman's and Tversky's (1979) prospect theory, which evaluated framing effects in terms of gains or losses. The gains and losses implication of prospect the theory can be interpreted and described in the positive and negative frames in the context of mass media framing effects of protest movements (supporting protests as a change outcome and supporting protests as a crisis outcome). According to Levin et al. (1998), framing in the positive or negative direction involves emphasizing either the potential gains or the potential losses of both options to the haggling parties. Thus, the findings of the metaanalytic review show that mass media framing effects of protest movements are stronger in the status quo support than in the protesters/protest support counterparts.

"Support for the status quo is the product of influences that have been classified into several categories including the biases individual journalists, professional conventions, practice, and ideologies, organizational, imperative, economic ties, sociocultural world views, and hegemonic ideologies" (McLeod \& Detenber, 1999, p. 4).

The findings of this meta-analysis show that support for the status quo become stronger effects than support for protests/protesters may be due to the preceding factors. 
Table 4. Subgroup analysis on the support for status quo and support for protest/protester of the studies

\begin{tabular}{lccccc}
\hline Frame direction of the studies & $\begin{array}{c}\text { Number of the } \\
\text { studies }\end{array}$ & $\%$ & $\begin{array}{c}\text { Effect size estimates } \\
(95 \% \mathrm{Cl})\end{array}$ & $\begin{array}{c}\text { Heterogeneity } \\
\left(\mathrm{I}^{2}\right)\end{array}$ & $\mathrm{p}$-value \\
\hline Status quo support & 26 & 68.42 & $0.362(0.181,0.543)$ & $99.35 \%$ & $\mathrm{p}<0.001$ \\
Protest/protesters' support & 11 & 26.32 & $0.329(0.205,0.454)$ & $96.56 \%$ & $\mathrm{p}<0.001$ \\
Overall & 37 & 100 & $0.352(0.220,0.484)$ & $99.17 \%$ & $\mathrm{p}<0.001$ \\
\hline
\end{tabular}

It can be understood that all positive frames for status quo had negative frames for protests/protesters and all positive frames for protesters/protests had negative frames for the status quo i.e., the high support news story for status quo presented in Table 4 were similar to the most negative portrayal of protesters/protests and vis-à-vis. In general, this result indicates that both negative and positive frames are importantly significant, and their repetitions and competition are very important for the effects of mass media on protest movements (Buturoiu \& Corbu, 2015). According to Levin et al. (1998), positive framings are more attributable than negative framings that means "positive framing supports more favorable evaluations and that negative framing supports less favorable evaluations" (p.164). Both parties, which means the status quo and protesters in the media coverage of protests tend to obtain positive consequences to gain positive framing effects. However, the contents of mass media on the framing of protests were either in the position of positive frames or negative frames due to internal and external factors associated with newsrooms. Such associations are attributed to media newsrooms through reporters or gatekeepers. Levin and Gaeth (1988) argued that information that tends to evoke supportive association to certain parties is labelled as positive to those parties, and information that does not support those parties is labelled as negative. Therefore, the positive encoding of protest news stories that support the status quo highlights positive framing aspects of information, whereas negative encoding of protest news stories does not support the status quo highlights negative framing aspects and vis-à-vis protesters.

\section{DISCUSSION}

Since the 1960 and 1970s, scholars in the fields of communication and sociology have contributed a lot to the development of farming as an important theoretical paradigm in media effect studies. They have authored and published several studies in peer-reviewed journals in the fields of media, communication, and sociology. However, Robert Entman was the first to propose framing as a theoretical paradigm in the 1990s (Entman, 1993). Since then, scholars' debates have continuously evolved over the years about the consistencies and inconsistencies of finding in framing research. Thus, the effects of media framing of political and social issues, especially protests and social movements have become the considerable interest of research areas in the field. However, the combined and aggregated researches on mass media framing of effects of the protest movement have been rarely investigated. To assess the framing function of the protest movement, and get a more reliable indication of the media's role in protest relationships over time, this study adopted a metaanalysis and systematic review approach for synthesizing the findings from existing studies published from 1990 to 2019.

This meta-analysis was based on 29 studies with $(k=37)$ cases that revealed a weighted grand mean effect size of $r=0.352$. According to Cohen (1992), an $r$ of $.10, .30$, and .50 are small, medium, and large effect sizes, respectively. Based on this criterion, the effect size of mass media framing for protests is medium in magnitude. The medium effect size in magnitude indicates that there is a likely visible effect in mass media framing of protests movement. A test of homogeneity of the effect size revealed that the grand mean correlation was significantly heterogeneous $\left(\mathrm{I}^{2}=99.17 \%\right.$ and $\left.\mathrm{Q}=4,330.52, \mathrm{df}=36, \mathrm{p}<.001\right)$, indicating that the inconsistencies in effect sizes are larger than what would be expected from sampling error alone (Hunter \& Schmidt, 1990).

This meta-analysis review considered three types of moderator variables, which include the basis of samples (content categories and survey participants), media type, and support for the status quo and support for the protesters/protesters. However, the significance of other moderators of media framing effect that include source characteristics, the longevity of framing effects, and the type of message identified by Buturoiu and Corbu (2015), need further investigation to fill one of the limitations of this meta-analysis. 
According to Bouliane (2015), the correlation coefficients of social media in protest activities are positively significant than the other media type since it offers free civic participation. To Valenzuela (2013), there is the strongest evidence of a positive relationship between social media use of protest movements. The pooled estimates of effect sizes among each moderator show that there is variability among each effect size that is bound to be variation in the effect sizes in a meta-analysis of every research (Rosenthal \& DiMatteo, 2001).

\section{Limitations and Future Research}

Evidence in literature has witnessed that meta-analyses and systematic reviews are exceptional in that they offer a systematic investigation within various field of studies though they cannot be free of weaknesses. One of the limitations was the restriction of studies selection to peer-reviewed studies published in the English language from 1990 to 2019. However, missing studies published in other languages, unpublished sources, excluding studies before 1990, and from other databases could alter the outcome if they had been included in the study. Secondly, the overall weighted mean effect size of this study may be confused because the sample sizes of the original studies were from several sources, and computing effect sizes of each study needed various formulas which may create inconsistencies. Thirdly, the absence of assessing other potential moderators of framing effects of mass media on protests movements such as source credibility, repetitive and competitive media exposure, and the importance of time as suggested by Buturoiu and Corbu (2015) would have been worth testing in which they may change results of this analysis if they had been added to this study. Hence, future research should consider such potential moderators or predictors that could yield greater confidence in conclusions and better estimates of the size of relationships between mass media framing and protests movement.

\section{CONCLUSIONS}

Mass media framing and protest movement are some of the most common interests of the research area in communication studies. The purpose of this meta-analysis was to compute a weighted mean effect size from a sample of studies and test moderating variables that may explain inconsistent findings in a body of research. This study offers two contributions to the consumption literature: 1) It systematically provides an aggregated picture of the effects of mass media framing of protest movements; 2 ) it has differentiated the extents of effect sizes of various studies in mass media framing of protest movement through testing of some moderating variables. This meta-analysis identified that there is a moderate weighted mean effect size of mass media framing of protest movements, which has a stronger effect on studies involving content categories than studies involving survey participants. The study also arrived at the effects of protest media framing is higher in the favor of status quo support than protesters/protesters' support. Regardless of some limitations in this meta-analytic review, which demand further research, the present study contributes to the communication literature by representing the influence of political communication in the context of mass media framing and exploring the diverse circumstances under which mass media framing of protest movement has a greater effect

Funding: The author received no financial support for the research and/or authorship of this article.

Declaration of interest: Author declares no competing interest.

Data availability: Data generated or analysed during this study are available from the authors on request.

\section{REFERENCES}

Anker E. A, Reinhart, M. A., \& Feeley, H. T. (2010). Meta-analysis of meta-analyses in communication: Comparing fixed effects and random effects analysis models. Communication Quarterly, 58(3), 257-278. https://doi.org/10.1080/01463373.2010.503154

Arpan, L. M., Baker, K., Lee, Y., Jung, T., Lorusso, L., \& Smith, J. (2006). News coverage of social protests and the effects of photographs and prior attitudes. Mass Communication \& Society, 9(1), 1-20. https://doi.org/10.1207/s15327825mcs0901_1

Banas, J. A., \& Rains, S. A. (2010). A meta-analysis of research on inoculation theory. Communication Monographs, 77(3), 281-311. https://doi.org/10.1080/03637751003758193 
Baylor, T. (1996). Media framing of movement protest: The case of American Indian protest. The Social Science Journal, 33(3), 241-255. https://doi.org/10.1016/S0362-3319(96)90021-X

Bennett, W. L., \& Segerberg, A. (2015). Communication in movements. In D. Della Porta, \& M. Diani (Eds.), The Oxford handbook of social movements, 367-382. Oxford University Press.

Borenstein, M., Hedges, L. V., Higgins, J. P. T., \& Rothstein, H. R. (2009). Introduction to meta-analysis. John Wiley. https://doi.org/10.1002/9780470743386

Boulianne, S. (2015). Social media use and participation: A meta-analysis of current research. Information, Communication \& Society, 18, 524-538. https://doi.org/10.1080/1369118X.2015.1008542

Boykoff, J. (2006). Framing dissent: Mass-media coverage of the global justice movement. New Political Science, 28(2), 201-228. https://doi.org/10.1080/07393140600679967

Boyle, M. P., McLeod, D. M., \& Armstrong, C. L. (2012). Adherence to the protest paradigm: The influence of protest goals and tactics on news coverage in U.S. and international newspapers. The International Journal of Press/Politics, 17(2), 127-144. https://doi.org/10.1177/1940161211433837

Brasted, M. (2005). Framing protest: The Chicago Tribune and the New York Times during the 1968 Democratic Convention. Atlantic Journal of Communication, 13(1), 1-25. https://doi.org/10.1207/s15456889ajc1301_1

Buturoiu, D. R., \& Corbu, N. (2015). Moderators of framing effects on political attitudes: Is source credibility worth investigating? Central European Political Studies Review, 17, 155-177. https://doi.org/10.5817/ CEPSR.2015.2.155

Card, N. (2012). Applied meta-analysis for social science research. Guilford Press.

Carragee, K., \& Roefs, W. (2004). The neglect of power in recent framing research. Journal of Communication, 54(2), 214-233. https://doi.org/10.1111/j.1460-2466.2004.tb02625.x

Chong, D., \& Druckman, J.N. (2007). A theory of framing and opinion formation in competitive elite environments. Journal of Communication, 57(1), 99-118. https://doi.org/10.1111/j.1460-2466.2006. 00331.x

Cohen, J. (1992). A power primer. Psychological Bulletin, 112, 155-159. https://doi.org/10.1037//0033-2909. 112.1.155

Cooper, A. H. (2002). Media framing and social movement mobilization: German peace protest against INF missiles, the Gulf War, and NATO peace enforcement in Bosnia. European Journal of Political Research, 41, 37-80. https://doi.org/10.1111/1475-6765.00003

Cooper, H., Hedges, L. V., \& Valentine, J. C. (2019). The handbook of research synthesis and meta-analysis. SAGE. https://doi.org/10.7758/9781610448864

D'Angelo, P. (2002). News framing as a multiparadigmatic research program: A response to Entman. Journal of Communication, 52, 870-888. https://doi.org/10.1111/j.1460-2466.2002.tb02578.x

D'Angelo, P. (2017). Framing: Media frames. In P. Roessler, C. A. Hoffner, \& L. van Zoonen (Eds.), The international encyclopedia of media effects (pp. 1-10). Wiley. https://doi.org/10.1002/9781118783764. wbieme0048

Entman, R. M. (1993). Framing: Toward a clarification of a fractured paradigm. Journal of Communication, 43, 51-58. https://doi.org/10.1111/j.1460-2466.1993.tb01304.x

Gitlin, T. (1980). The whole world is watching: Mass media and the making and unmaking of the newleft. University of California Press.

Goffman, E. (1974). Frame analysis. Northeastern University Press.

Goh, D., \& Pang, N. (2016). Protesting the Singapore government: The role of collective action frames in social media mobilization. Telematics and Informatics, 33(2), 525-533. https://doi.org/10.1016/j.tele.2015.07.008

Hari, S. I. (2014). The evolution of social protest in Nigeria: The role of social media in the "\# OccupyNigeria" protest. International Journal of Humanities and Social Science Invention, 3(9), 33-39.

Hedges, L. V., \& Vevea, J. L. (1998). Fixed-and random-effects models in meta-analysis. Psychological Methods, 3(4), 486-504. https://doi.org/10.1037/1082-989X.3.4.486

Hunter, J. E., \& Schmidt, F. L. (1990). Methods of meta-analysis: Correcting error and bias in research findings. SAGE.

Kahneman, D., \&Tversky, A. (1979). Prospect theory: An analysis of decision under risk. Econometrica, 47, 263291. https://doi.org/10.2307/1914185

Kaun, A. (2017). 'Our time to act has come': Desynchronization, social media time and protest movements. Media, Culture \& Society, 39(4), 469-486. https://doi.org/10.1177/0163443716646178 
Ketelaars, P. (2017). Tracing protest motives: The link between newspaper coverage, movement messages, and demonstrators' reasons to protest. Sociological Forum, 32(3), 480-500. https://doi.org/10.1111/ socf. 12345

Kilgo, D. K., \& Harlow, S. (2019). Protests, media coverage, and a hierarchy of social struggle. The International Journal of Press/Politics, 24(4), 508-530. https://doi.org/10.1177/1940161219853517

Lee, S. (2018). The role of social media in protest participation: The case of candlelight vigils in South Korea. International Journal of Communication, 12, 18.

Leopold, J., \& Bell, M. P. (2017). News media and the racialization of protest: An analysis of Black lives matter articles. Equality, Diversity and Inclusion: An International Journal. 36(8), 720-735. https://doi.org/10.1108/ EDI-01-2017-0010

Levin, I. P., \& Gaeth, G. J. (1988). How consumers are affected by the framing of attribute information before and after consuming the product. Journal of Consumer Research, 15(3), 374-378. https://doi.org/ $10.1086 / 209174$

Levin, P. I., Schneider L. S., \& J. Gaeth, J. G. (1998). All frames are not created equal: A typology and critical analysis of framing effects. Organizational Behavior and Human Decision Processes, 76(2), 49-188. https://doi.org/10.1006/obhd.1998.2804

Liberati, A., Altman, D. G., Tetzlaff, J., Mulrow, C., Gøtzsche, P. C., Ioannidis, J. P.A., Clarke, M., Devereaux, P.J., Kleijnen, J., \& Moheret, D. (2009). The PRISMA statement for reporting systematic reviews and metaanalyses of studies that evaluate health care interventions: Explanation and elaboration. BMJ, 339. https://doi.org/10.1136/bmj.b2700

Lipsey, M. W. (2003). Those confounded moderators in meta-analysis: Good, bad, and ugly. Annals of the American Academy of Political and Social Science, 587, 69-81. https://doi.org/10.1177/0002716202250791

Lipsey, M., \& Wilson, D. (2001). Practical meta-analysis. SAGE.

Luo, Y., Burley H., Moe, A., \& Sui, M. (2019). A meta-analysis of news media's public agenda-setting effects, 1972-2015. Journalism \& Mass Communication Quarterly, 96(1), 150-172. https://doi.org/10.1177/1077699018804500

Mac Sheoin, T. (2013). Framing the movement, framing the protests: Mass media coverage of the antiglobalization movement. Interface, 5(1), 272-365.

McCombs, M. E., \& Shaw, D. L. (1972). The agenda-setting function of mass media. Public Opinion Quarterly, 36, 176-187. https://doi.org/10.1086/267990

McLeod, D. M. (2007). News coverage and social protest: How the media's protect paradigm exacerbates social conflict. Journal of Dispute. Resolution, 185-194. https://scholarship.law.missouri.edu/jdr/vol2007/iss1/12

McLeod, D. M., \& Detenber, B. H. (1999). Framing effects of television news coverage of social protest. Journal of Communication, 49(3), 3-23. https://doi.org/10.1111/j.1460-2466.1999.tb02802.x

McLeod, D. M., \& Hertog, J. K. (1992). The manufacture of public opinion by reporters: Informal cues for public perceptions of protest groups. Discourse and Society, 3, 259-275. https://doi.org/10.1177/ 0957926592003003001

McLeod, D. M., \& Hertog, J. K. (1999). Social control and the mass media's role in the regulation of protest groups: The communicative acts perspective. In D. Demers, \& K. Viswanath (Eds.), Mass media, social control and social change (pp. 305-330). lowa State University Press.

Rosenthal, R., \& DiMatteo, M. R. (2001). Meta-analysis: Recent developments in quantitative methods for literature reviews. Annual Review of Psychology, 52, 59-82. https://doi.org/10.1146/annurev.psych.52.1.59

Scheufele, B. (2004). Framing-effects approach: A theoretical and methodological critique. Communications, 29, 401-428. https://doi.org/10.1515/comm.2004.29.4.401

Shoemaker, P. J. (1982). The perceived legitimacy of deviant political groups: Two experiments on media effects. Communication Research, 9, 249-286. https://doi.org/10.1177/009365082009002004

Shoemaker, P. J. (1984). Media treatment of deviant political groups. Journalism Quarterly, 61(1), 66-82. https://doi.org/10.1177/107769908406100109

Surzhko-Harned, L., \& Zahuranec, A. J. (2017). Framing the revolution: The role of social media in Ukraine's Euromaidan movement. Nationalities Papers, 45(5), 758-779. https://doi.org/10.1080/00905992.2017. 1289162 
Valenzuela, S. (2013). Unpacking the use of social media for protest behavior: The roles of information, opinion expression, and activism. American Behavioral Scientist, 57(7), 920-942. https://doi.org/10.1177/0002764213479375

Wanta, W., \& Wu, Y. C. (1992). Interpersonal communication and the agenda-setting process. Journalism \& Mass Communication Quarterly, 69, 847-855. https://doi.org/10.1177/107769909206900405

Watkins, C. S. (2001). Framing protest: News media frames of the million-man march. Critical Studies in Media Communication, 18(1), 83-101. https://doi.org/10.1080/15295030109367125

Wouters R., \& Walgrave, S. (2017). Demonstrating power: How protest persuades political representatives. American Sociological Review, 82(2), 361-383. https://doi.org/10.1177/0003122417690325

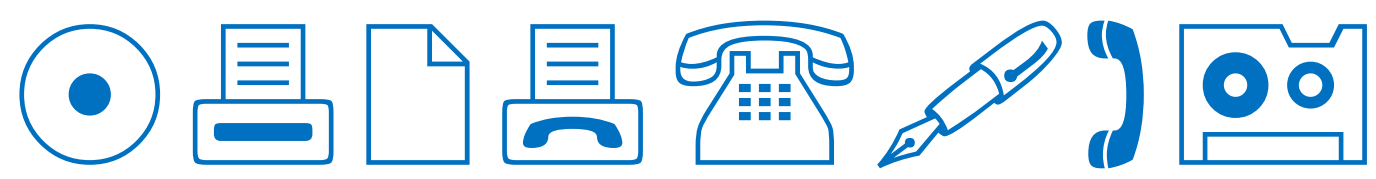

